Int. J. Dev. Biol. 61: 545-550 (2017)

doi: $10.1387 / \mathrm{ijdb} .160344 \mathrm{kw}$

\title{
Neurosphere formation potential resides not in the caudal cell mass, but in the secondary neural tube
}

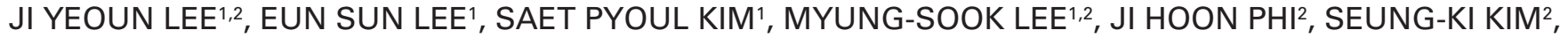 \\ YOUNG-IL HWANG ${ }^{1}$ and KYU-CHANG WANG ${ }^{*}, 1,2$
}

\begin{abstract}
${ }^{1}$ Neural Development and Anomaly Laboratory, Department of Anatomy and Cell Biology, Seoul National University College of Medicine, Seoul, Korea and 'Division of Pediatric Neurosurgery, Seoul National University Children's Hospital, Seoul, Korea
\end{abstract}

\begin{abstract}
The caudal cell mass (CCM) is known as the main player in secondary neurulation, forming the secondary neural tube (2NT). This suggests that the CCM may have the character of neural progenitor cells. The neural potential of the CCM and the 2NT (CCM + 2NT) was assessed by in vitro culture of neurospheres during Hamburger and Hamilton stages $(\mathrm{HH})$ of secondary neurulation (HH16 to HH32). We also analyzed the neural potential of the developing central nervous system (CNS) by comparing the neurosphere culture from the brain, upper / lower spinal cord, and $\mathrm{CCM}+2 \mathrm{NT}$ from various HH stages. The CCM + 2NT was capable of forming neurospheres. Of the various $\mathrm{HH}$ stages, the greatest number of neurospheres from CCM + 2NT were cultured at $\mathrm{HH} 28$. Because the 2NT is most prominent at HH28, we hypothesized that the 2NT, rather than the CCM, had the main potential to produce neurospheres. When the neurospheres were cultured separately from the CCM and the 2NT, 2NT made significantly more neurospheres. When comparing different parts of the CNS, at HH16, the greatest number of neurospheres was formed from the brain. At $\mathrm{HH} 32$, it was the $\mathrm{CCM}+2 \mathrm{NT}$. The region with the greatest number of neurospheres progressed in a cephalo-caudal direction during development. This study showed that neurospheres can be cultured from $\mathrm{CCM}+2 \mathrm{NT}$, and the main player in neurosphere formation was the $2 \mathrm{NT}$. The present study has also revealed cephalo-caudal trend in the neural potential of developing CNS.
\end{abstract}

KEY WORDS: caudal cell mass, secondary neural tube, neurosphere, neural progenitor, development

The vertebrate brain and spinal cord are formed by neurulation, which is composed of two processes termed primary and secondary neurulation. Primary neurulation is well-known to form the brain and most of the spinal cord from the cervical to the upper sacral level. Various molecular pathways and genetic factors have been identified in relation to primary neurulation (Copp et al., 2013; LeDouarin, 2011). Secondary neurulation is responsible for the lower sacral and coccygeal levels of the vertebrae and spinal cord. This process is not as well understood as primary neurulation. It is thought that a group of undifferentiated mesenchymal cells, called the tail bud or caudal cell mass (CCM), undergoes roughly three steps of condensation, cavitation, and degeneration, during which the secondary neural tube (2NT) is formed (Muller and O'Rahilly, 1987, Schoenwolf and Delongo, 1980). However, the molecular mechanisms underlying these steps are largely unknown. Despite the scarcity of scientific research on this topic, the clinical importance of secondary neurulation has been increasing. With active maternal folate intake and meticulous prenatal diagnosis, the birth prevalence of congenital anomalies related to primary neurulation (example: myelomeningocele) has decreased substantially during the past three decades, especially in more advanced societies. On the other hand, the birth prevalence of congenital anomalies related to secondary neurulation (e.g., lumbosacral lipomatous malformation, terminal myelocystocele, thickened filum) has not decreased during the same period (Copp et al., 2013). The latter has instead been increasingly diagnosed and treated with the advancement in diagnostic tools such as MRI.

One of the topics to be explored regarding secondary neurulation is the CCM. As it has been generally hypothesized that this mass of undifferentiated mesenchymal cells gives rise to neuroepithelium (Krenn et al., 1990), the presence of a "neural progenitor" character has been studied intensively. As there is line

Abbreviations used in this paper: 2NT, secondary neural tube; CCM, caudal cell mass; $\mathrm{HH}$, Hamburger and Hamilton stage. *Address correspondence to: Kyu-Chang Wang. Division of Pediatric Neurosurgery, Seoul National University Children's Hospital, 101 Daehak-ro, Jongno-gu,
Seoul, 110-744, Republic of Korea.Tel: 82-2-2072-3489. Fax: 82-2-744-8459. E-mail: kcwang @ snu.ac.kr (D) http://orcid.org/0000-0001-7440-6650 
of evidence that neural stem cells exist and neurospheres have been cultured in other parts of the developing central nervous system (CNS) (Kalyani et al., 1997, Scott et al., 2010), this study aimed to elucidate whether the CCM and 2NT have the potential to generate neurospheres in vitro. First, neurosphere formation assay was performed using $\mathrm{CCM}+2 \mathrm{NT}$ at the early Hamburger and Hamilton stage ( $\mathrm{HH}$ (Hamburger and Hamilton, 1992)) of secondary neurulation. After confirming that CCM $+2 \mathrm{NT}$ had the potential to generate neurospheres, the experiment was done throughout the secondary neurulation. The CCM and the 2NT was separated to assess the neurosphere generation potential for each at $\mathrm{HH} 2 \mathrm{O}$ and $\mathrm{HH} 28$. Lastly, spatiotemporal dynamic of neurosphere formation was explored by analyzing the potential in the entire length of the developing CNS. Although the term "CCM" may refer to both the cell mass itself as well as the secondary neurulation structures in other reports, in the present study, "CCM" will strictly mean the pure cell mass, and "CCM $+2 \mathrm{NT}$ " will annotate the tissue consisting of $\mathrm{CCM}$ and also its derivative.

\section{Results}

\section{Neurosphere culture from caudal cell mass + secondary neural tube of HH stage 16 chick embryos}

As whether the CCM + 2NT had the potential to generate neurospheres in vitro had not been evaluated, we first attempted to perform neurosphere formation assay using the CCM + 2NT from $\mathrm{HH} 16$ embryos. Because the CCM is known to be most prominent at $\mathrm{HH} 16$, we began the evaluation of the presence of neurospheres at this $\mathrm{HH}$ stage (Fig. 1). CCM + 2NT was dissected under the microscope, enzymatically dissociated, and plated with growth factors ( $5 \times 10^{5}$ cells per dish). It should be noted that the proportion of the 2NT at this stage is minimal, because 2NT formation usually starts at about $\mathrm{HH} 14$ to $\mathrm{HH} 16$.

Neurospheres were successfully cultured from the CCM $+2 \mathrm{NT}$ of $\mathrm{HH} 16$ chick embryos. By the $4^{\text {th }}$ day in culture, more than 10
A

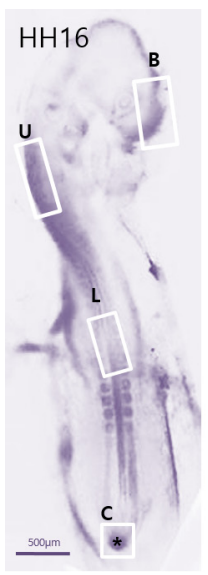

B
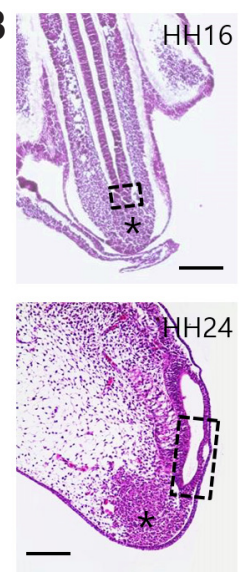

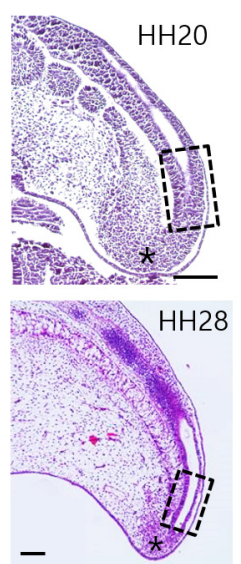

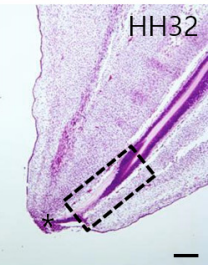

Fig. 1. Marking of specific dissected tissues on the gross photograph $(A)$ and H\&E sections (B) of chick embryo sample. (A) The anatomic landmark for upper spinal cord was the hind brain and wing bud, and for the lower spinal cord, the

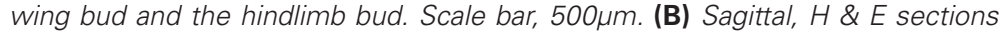
of the CCM + 2NT at different stages. The dotted box denotes the 2NT, and the asterisk to the CCM itself. Scale bar, $100 \mu \mathrm{m}$. B: brain, U: upper spinal cord, L: lower spinal cord, C: CCM + 2NT, CCM: caudal cell mass, 2NT: secondary neural tube, HH: Hamburger \& Hamilton stage.
TABLE 1

NUMBER OF NEUROSPHERES FORMATION FROM CAUDAL CELL MASS AND BRAIN IN CHICK EMBRYOS

\begin{tabular}{ccc}
$\begin{array}{c}\text { Hamburger and Hamilton stage } \\
(\mathbf{H H})\end{array}$ & $\begin{array}{c}\text { Caudal cell mass } \\
\text { (mean } \pm \text { SD) }\end{array}$ & $\begin{array}{c}\text { Brain } \\
\text { (mean } \pm \text { SD) }\end{array}$ \\
\hline HH16 & $57.6 \pm 8.2^{*}$ & $379.1 \pm 39.8$ \\
HH20 & $102.3 \pm 13.0^{*}$ & $240.4 \pm 27.6$ \\
HH24 & $189.8 \pm 19.7$ & $120.0 \pm 19.7$ \\
HH28 & $235.4 \pm 14.4^{*}$ & $66.5 \pm 6.8$ \\
HH32 & $150.4 \pm 18.1^{*}$ & $21.6 \pm 6.2$ \\
\hline
\end{tabular}

* $\mathrm{p}<0.05$ Caudal cell mass vs Brain (Mann-Whitney $\mathrm{U}$ test, $\mathrm{N} \geq 5$ per group.

neurospheres had appeared. At the $6^{\text {th }}$ day in culture, an average of $57.6 \pm 8.2$ spheres $/ 5 \times 10^{5}$ viable cells were found. The neurospheres were positively stained for the neural progenitor cell markers Sox2 and nestin (Fig. 2A). Additionally, the spheres were confirmed to be maintained up to at least 3 passages, showing the self-renewal ability. The neurospheres from the CCM + 2NT were able to generate all three neural cell lineages (neurons, astrocytes, and oligodendrocytes), as revealed by the expression of cell-specific markers, tubulin $\beta 3$, GFAP, MBP respectively (Fig. 2 B,C).

\section{Quantitative analyses of neurosphere culture from the caudal cell mass + secondary neural tube during various develop- mental $\mathrm{HH}$ stages}

The proof of neurosphere formation potential in the CCM + 2NT of the chick embryo led us to examine whether neurospheres can be formed in the $\mathrm{CCM}+2 \mathrm{NT}$ throughout the later stages of development. The neurosphere assay was performed using the $\mathrm{CCM}+2 \mathrm{NT}$ (the asterisk plus the dotted box in Fig. 1) from chick embryos at $\mathrm{HH} 16, \mathrm{HH} 20, \mathrm{HH}_{2} 4, \mathrm{HH} 28$, and $\mathrm{HH} 32$ to compare the number of neurospheres formed and their rate of formation.

The results suggest that the neurosphere generation potential of the CCM + 2NT varied during the course of development. The number of spheres increased significantly as the developmental stage advanced, and the greatest number of neurospheres at the $6^{\text {th }}$ day of culture was generated from $\mathrm{HH} 28$ embryos. An average of $235.4 \pm 14.4$ spheres / $5 \times 10^{5}$ cells was found for $\mathrm{HH} 28$, which is 4-fold greater than the number of neurospheres formed from HH16 (Table 1). Additionally, the latency to neurosphere appearance, defined as the day when 10 neurospheres had formed, was shorter in the samples from later stages of development. The CCM cells of $\mathrm{HH} 16$ required 3.5 days to generate more than 10 neurospheres, whereas neurosphere formation required only 1.6 days for HH32 embryos (Fig. 2D, red line). The differential potential and self-renewal ability were confirmed for all the $\mathrm{HH}$ stages examined as described for $\mathrm{HH} 16$.

\section{Quantitative analyses of neurosphere culture from the} caudal cell mass or secondaryneural tube at HH2Oand 28

The dynamic trend of neurosphere formation potential (increase from $\mathrm{HH} 16$ to $\mathrm{HH} 28$ ) corresponds to the course of 2NT formation from the CCM, ie the proportion of CCM compared to the 2NT. Therefore, we evaluated whether the main player forming the neurosphere was the CCM or the 2NT. The CCM (the asterisk in Fig. 1) and 2NT (the dotted box in Fig. 1) was separated in $\mathrm{HH} 20$ and $\mathrm{HH} 28$. Neurosphere assay was performed separately for each. 
A
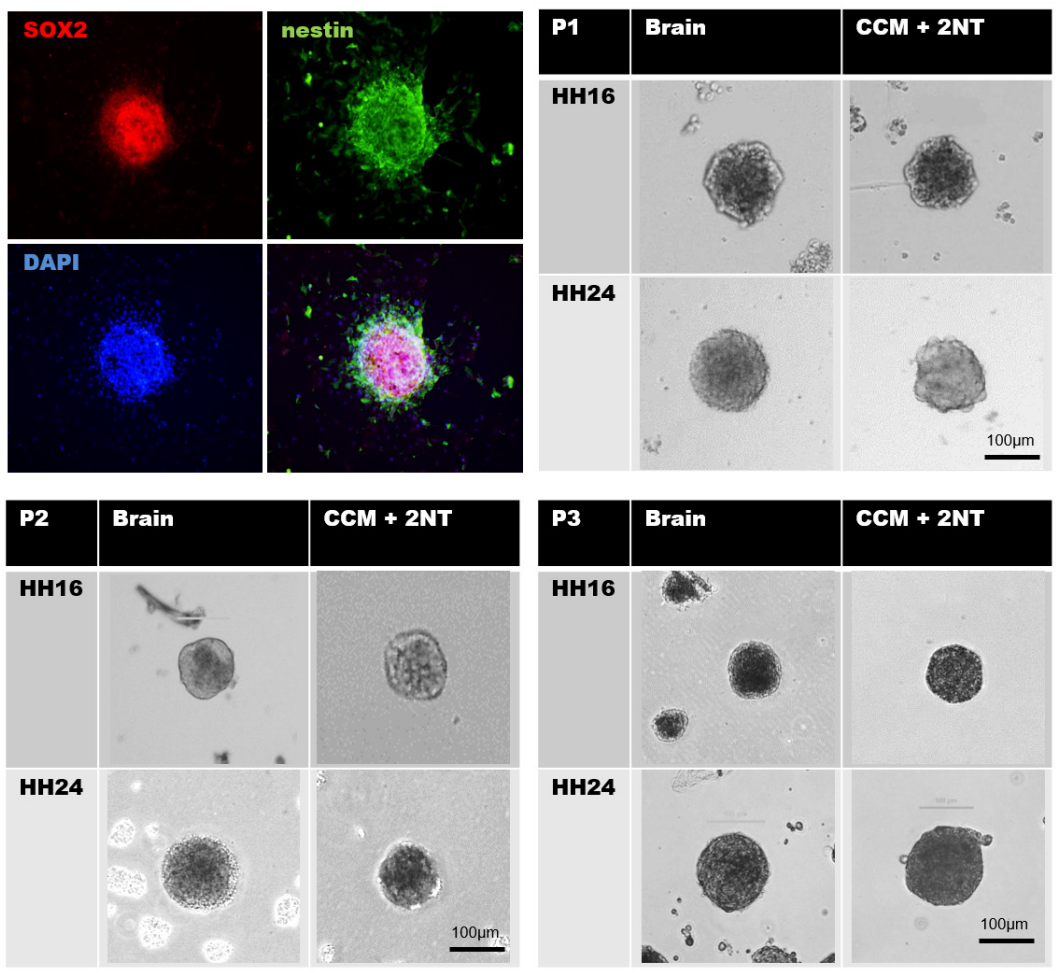

B
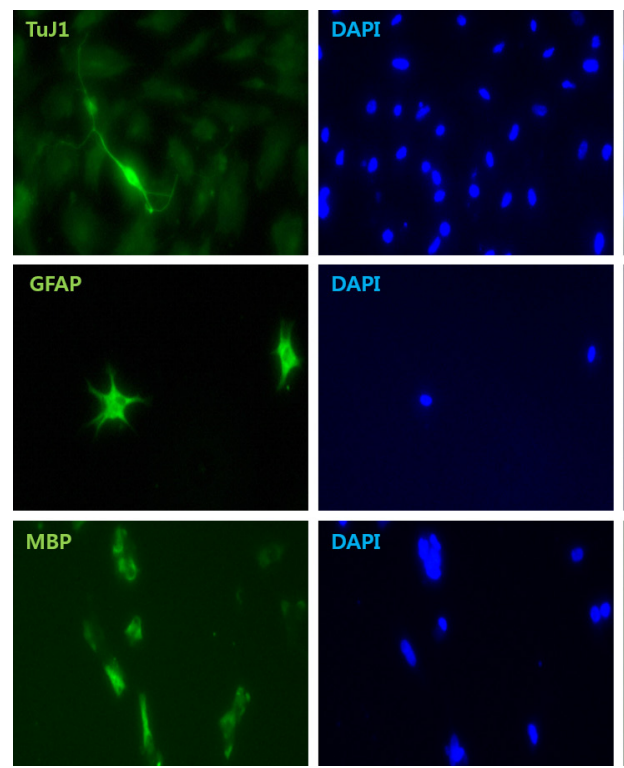

D

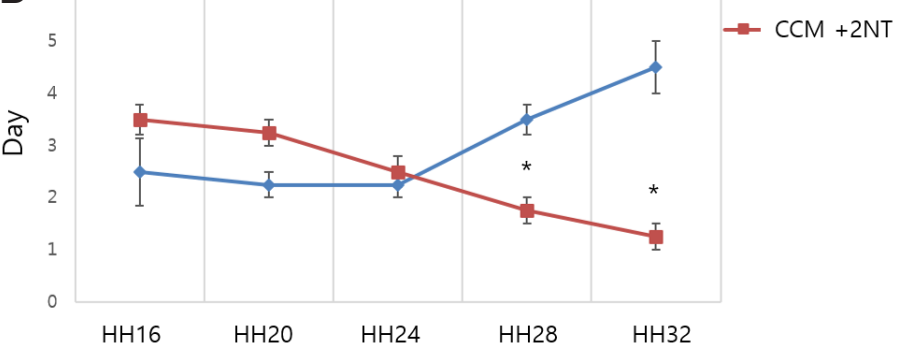

The results showed that the CCM without 2NT poorly spheres / $5 \times 10^{5}$ cells and $68.75 \pm 14.05$ spheres $/ 5 \mathrm{x}$ $10^{5}$ cells; at HH28 were $45.57 \pm 5.98$ spheres / $5 \times 10^{5}$ cells and $101.0 \pm 21.45$ spheres $/ 5 \times 10^{5}$ cells (CCM and 2NT, respectively for each stage; Fig. $3 A$ ).

\section{Comparison of the neurosphere generation potential of various CNS regions during development}

To assess the spatiotemporal difference in the potential of the developing neural system, we further tested the neurosphere formation ability of the brain and spinal cord at different time points during development.

Cells were cultured from the brain and spinal cord of $\mathrm{HH} 16, \mathrm{HH} 20, \mathrm{HH} 24, \mathrm{HH} 28$, and HH32. To elucidate the differences between cephalic and caudal regions, the spinal cord was divided into the upper (cephalad to the wing bud, mostly cervical and upper thoracic cord) and lower spinal cord (the segments between wing bud and hind limb bud). Cells from the brain, upper spinal cord, lower spinal cord, and CCM + 2NT were cultured, and the neurosphere formation was quantified.

Neurosphere formation was most active for the brain tissue at $\mathrm{HH} 16,379.1 \pm 39.8$ spheres $/ 5 \times 10^{5}$ cells by the $6^{\text {th }}$ day of culture. The number of neurospheres progressively decreased until HH32 (21.6 \pm 6.2 spheres / 5 made neurospheres, compared to the 2NT. The number of neurospheres formed at $\mathrm{HH} 20$ were $10.75 \pm 3.12$
C
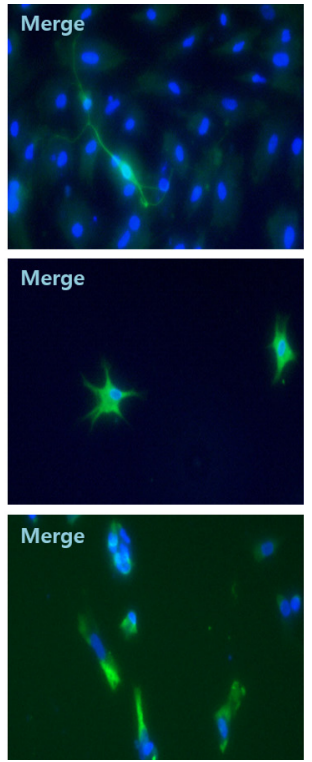
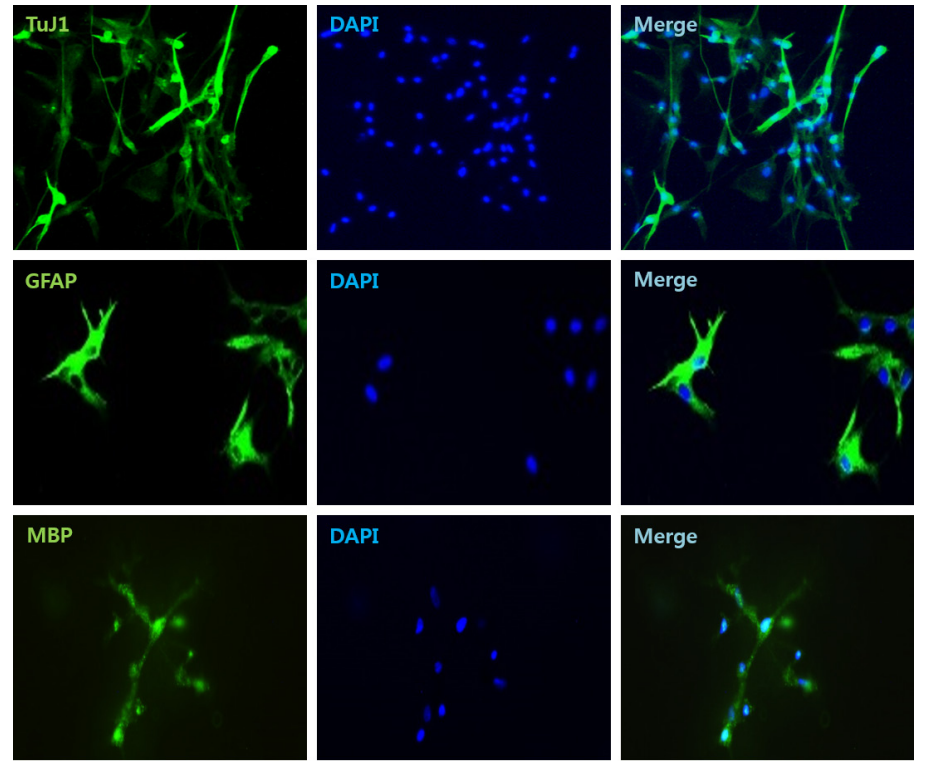

Fig. 2. Details of neurospheres cultured from caudal cell mass (CCM) + secondary neural tube (2NT). (A) The representative morphology of neurospheres cultured from brain and CCM + 2NT following 3 passages (P1, P2, P3). All were positive for Sox2 and nestin. (B,C) Successful differentiation of the NSC from (B) brain and from (C) CMM $+2 N T$ into neuron (Tuj1), astrocyte (GFAP), and oligodendrocyte (MBP). (D) Linear plot of the day of sphere formation from different stages of brain vs CCM $+2 N T$. The $C C M+2 N T$ seem to take less time to form neurospheres as development progresses, whereas for the brain, the time increases from $\mathrm{HH} 24$ and on. *; $p<0.05 C C M+2 N T$ versus brain of same stage by Mann-Whitney $U$ test. HH, Hamburger \& Hamilton stage. 
$x 10^{5}$ cells, which is $5.5 \%$ of that of cells from $\mathrm{HH} 16$ brain) (Table 1 ). Similarly, the first day of sphere formation was significantly delayed for HH28 and HH32 than for earlier HH stages (Fig. 2D, blue line).

For both the upper and lower spinal cord, the neurosphere generation potential increased from $\mathrm{HH} 16$ to $\mathrm{HH} 28$ and decreased at $\mathrm{HH} 32$. The number of neurospheres at the $6^{\text {th }}$ day of culture peaked at $\mathrm{HH} 28$ for both the upper $\left(88.0 \pm 17.4\right.$ spheres $/ 5 \times 10^{5}$ cells) and lower spinal cord (172.5 \pm 30.4 spheres $/ 5 \times 10^{5}$ cells). However, the increase in number was more prominent in the lower spinal cord, almost comparable to the trend observed for CCM + 2NT. In other words, the upper spinal cord had actually produced more neurospheres than the lower spinal cord at HH16 (upper spinal cord, $44.0 \pm 36.8$ spheres $/ 5 \times 10^{5}$ cells; lower spinal cord, $32.5 \pm 26.2$ spheres $/ 5 \times 10^{5}$ cells), but the increase in the neurosphere count for the upper spinal cord was minimal compared to the lower spinal cord.

In summary, the number of neurospheres cultured from the $\mathrm{CCM}+2 \mathrm{NT}$ significantly increased as development proceeded, peaking at $\mathrm{HH} 28$. The potential of the brain to form neurospheres peaked at $\mathrm{HH} 16$ and subsequently decreased. Both the upper and lower spinal cord showed peak neurosphere generation at $\mathrm{HH} 28$, similar to the $\mathrm{CCM}+2 \mathrm{NT}$, but the absolute sphere count was greatest for the lower spinal cord at this stage. At $\mathrm{HH}_{32}$, only the $\mathrm{CCM}+2 \mathrm{NT}$ retained the ability to generate a significant number of neurospheres, although this was decreased compared to $\mathrm{HH} 28$ (Fig. 3B).

\section{Discussion}

This study used in vitro neurosphere culture to assess the characteristics of the CCM and the 2NT as neural progenitors, and the neurosphere formation potentials were compared with the entire developing CNS. First, this study showed that the CCM + 2NT in chick embryos have the potential to generate neurospheres in vitro. Furthermore, although neurospheres could be cultured from the $\mathrm{CCM}+2 \mathrm{NT}$ in all the stages examined, the quantitative potential of neurosphere formation increased as development advanced from $\mathrm{HH} 16$ to HH28. By separation of CCM and 2NT, we found that CCM had very limited potential to produce neurospheres, and instead 2NT was the main player to produce neurospheres. Second, via in vitro culture of neurospheres from tissues of the brain, upper and lower spinal cord, and CCM + 2NT, this study further evaluated the spatiotemporal differences in the neurosphere formation potential of the entire neural axis. Compared to the CCM $+2 \mathrm{NT}$, the brain showed the opposite trend, with the number of neurospheres peaking at $\mathrm{HH} 16$ and decreasing as development progressed. A cephalo-caudal trend (brain $\rightarrow$ upper spinal cord $\rightarrow$ lower spinal cord $\rightarrow \mathrm{CCM}+2 \mathrm{NT}$ ) was seen for the regions with the largest number of neurospheres as development progressed (HH16 to HH32).

The first part of the study showed that the neurosphere formation potential of the CCM + 2NT seems to change during development in accordance to the course of secondary neurulation and the corresponding changes in the $\mathrm{CCM}+2 \mathrm{NT}$ as shown in Figs. 1-2. Briefly, the $\mathrm{CCM}$ is most prominent at $\mathrm{HH} 16$ and gradually disappears as secondary neurulation progresses (Yang et al., 2003). By HH28, the secondary neural tube formation is almost complete, and the decrease in the relative size of CCM is progressing which means that the secondary neural tube is most prominent at this stage
A

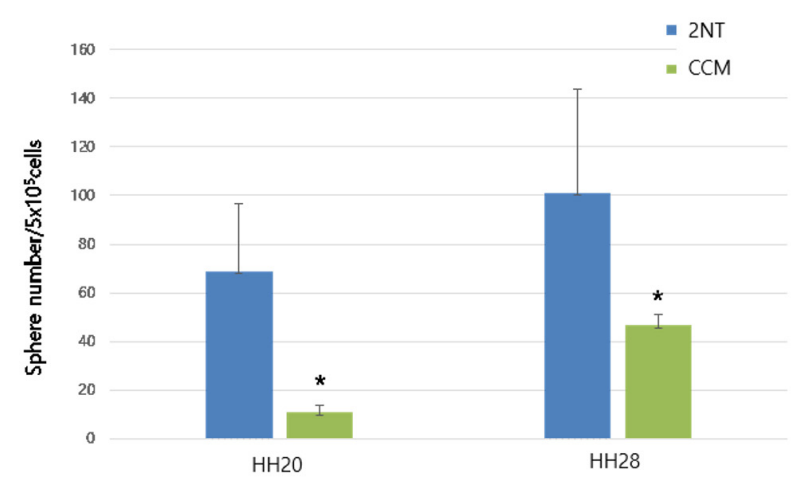

B

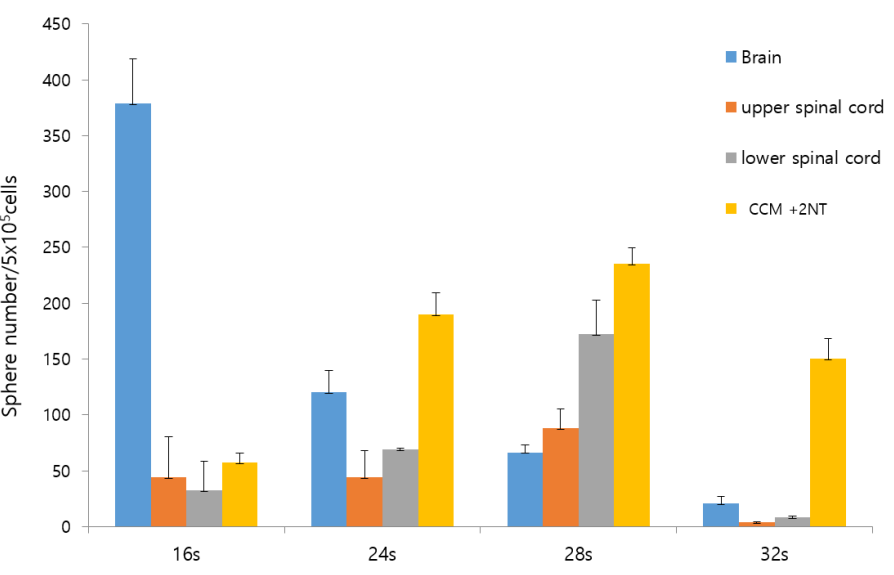

Fig. 3. Comparison of number of neurospheres cultured from the secondary neural tube (2NT) vs. caudal cell mass (CCM) and various regions of the CNS. (A) Quantification of neurospheres from CCM + 2NT at 6 days of culture after plating $5 \times 10^{5}$ cells for HH2O and HH28. Data are shown as mean $\pm S E M ; n \geq 4 ;{ }^{*}, p<0.05$ CCM versus $2 N T$. (B) Quantification of neurospheres from brain, upper spinal cord, lower spinal cord, and CCM and $+2 \mathrm{NT}$ at 6 days of culture after plating $5 \times 10^{5}$ cells for HH16, HH24, HH28, and HH32. CCM: caudal cell mass, 2NT: secondary neural tube, HH: Hamburger \& Hamilton stage.

(Schoenwolf, 1979, Yang et al., 2003). Therefore, the trend of the increase in the number of neurospheres produced by CCM + 2NT seems to correspond to the increase in the relative proportion of the 2NT compared to the CCM. This suggests the possibility that it is the 2NT, and not the CCM that has the potential to produce neurospheres in vitro. By comparing the neurosphere formation between the CCM and 2NT separately, we showed that CCM made less neurospheres. A recent study evaluating the neurosphere formation potential of the 2NT in mouse embryo also observed a similar phenomenon in which the pure CCM failed to generate neurospheres in vitro, and only the tube-forming, cavitated structure consisting of the 2NT successfully generated neurospheres (Shaker et al., 2015). It is also interesting to note that the filum terminale, a remnant of the 2NT, has been shown to have the character of a neural progenitor niche in both rats and humans (Chrenek et al., 2017).

That CCM has very little potential to neurospheres in vitro is surprising, as the 2NT is derived from the CCM. However, the result of this study is in line with recent evidence of the existence of bipotent progenitors (the neuro-mesodermal progenitor) in the 
CCM (Henrique et al., 2015). Because the majority of the cells in the CCM are bipotent and at an earlier stage in lineage commitment than the purely neural progenitors, the neural character is obtained as the cells form the 2NT. This may provide one explanation of why the potential to form neurospheres is much higher in the 2NT.

The second part of the study compared the neurosphere formation potential of the CCM + 2NT with other parts of the CNS at the same time point during development. The greatest potential for generating neurospheres was found in the brain during early development $(\mathrm{HH} 16)$, and it then gradually descended to the spinal cord and then to the CCM region until HH28. The temporal dynamics of the neurosphere generation potential of different regions of the CNS resembles the cephalo-caudal direction of neurodevelopment. Previous reports evaluating regional differences in the neurospheres derived from brain and spinal cord have also shown varying results according to the developmental stage of the samples. In adult mice, when the neurosphere formation potential was compared among various regions of the CNS (lateral ventricle, third ventricle, fourth ventricle, thoracic spinal cord, lumbar/sacral spinal cord), the greatest numbers of spheres were generated from the lateral ventricles of the brain and from the lumbosacral spinal cord (Weiss et al., 1996). When neurospheres formed from the forebrain and spinal cord were compared in embryonic day 16 rats, the brain produced neurospheres most actively, but the spinal cord was not divided into segments in this study (Fu et al., 2005). In still another study, no definite differences in sphere generation were observed between the brain and spinal cord of embryonic day 14 mice (Kelly et al., 2009). The inconsistencies among the previous reports and the present study regarding the relative potential for in vitro neurosphere generation may be attributable to species differences as well as to the developmental stages.

The significance of the chick embryo as an experimental animal for research on secondary neurulation should be noted. Rodents are the most common experimental animals in general because they are more closely related evolutionarily to humans than are avians. However, the secondary neurulation process in rodents is suspected to differ from that of humans, the 2NT forms by a direct extension of primary neurulation (Schoenwolf and Powers, 1987, Shedden and Wiley, 1987). There is evidence that in human, the 2NT forms as a separate structure from the primary neural tube, more closely resembling the development of the chick (Schoenwolf and Delongo, 1980, Yang et al., 2014). Therefore, the chick embryo seems to be a viable tool to study the secondary neurulation.

The limitation of the study is related to the difference between neurospheres in vitro and neural stem cells (NSCs). Neurospheres in vitro had been interpreted as equivalent to neural stem cells in vivo (Reynolds and Weiss, 1992, Temple, 2001). However, as the concept and definition of stem cells and the in vitro experiments have matured, the recent consensus is that the presence of neurospheres alone offers no certainty that stem cells are present in the aggregates nor the tissue of origin (Jensen and Parmar, 2006, Pastrana et al., 2011, Tavazoie et al., 2008). Therefore, the results of this study should not be extrapolated as proof that NSCs reside in the CCM or secondary neural tube. Studies with in vivo single cell tracking or neurosphere culture from true single cells showing self-renewal and multipotency will be more appropriate.

This study has documented for the first time the potential of the $\mathrm{CCM}+2 \mathrm{NT}$ from chick embryos to generate neurospheres in vitro. This work also elucidated the temporal change of the neurosphere generation potential during development. Combining the results of this study with the changes in the CCM + 2NT during the course of secondary neurulation, it seems that the main player in neurosphere generation may be the $2 \mathrm{NT}$, not the CCM.

\section{Materials and Methods}

\section{Tissue extraction and neurosphere culture}

$\mathrm{HH} 16, \mathrm{HH} 2 \mathrm{O}, \mathrm{HH} 24, \mathrm{HH} 28$ and $\mathrm{HH} 32$ were obtained by incubating fertile eggs (Pulmuone, Umsung, Korea) at $37.5{ }^{\circ} \mathrm{C}$ and $80 \%$ relative humidity. The embryos were removed from the eggs and washed in PBS. The relevant portion of the brain or spinal cord was dissected from the embryo. The CCM + 2NT were discriminated starting from the caudal end to a length equivalent to 3 somites. The transitional zone (overlap between primary and secondary neural tubes) (Yang et al., 2003) was not included. At $\mathrm{HH} 16$, the 2NT just starts to evolve from the CCM, therefore the dissected tissue consisted mostly of the CCM (the asterisk in Fig. 1). From $\mathrm{HH} 20$, the 2NT is prominent, cephalad to the CCM, therefore, the tissue used for neurosphere culture included the CCM as well as the 2NT (the dotted box in Fig. 1), and the term ' $\mathrm{CCM}+2 \mathrm{NT}$ (the asterisk plus the dotted box)' was used. For $\mathrm{HH} 20$ and $\mathrm{HH} 28$, additional neurosphere assay using separate CCM and 2NT was performed. The prosencephalon was dissected for brain cultures. The 'upper' spinal cord was defined as the spinal cord located caudal to the junction of the cranium and spine and rostral to the wing bud. The 'lower' spinal cord was defined as the spinal cord located between the wing bud and the hind limb bud. To separate the CCM and neural tube, tissues were microdissected by $2 \%$ trypsin digestion for 20-40min (Diez del Corral et al., 2002).

The tissue was mechanically dissociated, incubated with Accutase (Gibco, NY, USA) for $10 \mathrm{~min}$ at $37^{\circ} \mathrm{C}$, and passed through a sterile cell strainer (40 $\mu \mathrm{m}$ pores). The dissociated cell suspension was centrifuged at $200 \mathrm{~g}$ for $10 \mathrm{~min}$, and the pellet was washed once and then plated $(5 \mathrm{x}$ $10^{5}$ cells) in uncoated 6-well tissue-culture plates with media composed of DMEM/F-12 (1:1), supplemented with $20 \mathrm{ng} / \mathrm{ml}$ EGF, $10 \mathrm{ng} / \mathrm{ml} \mathrm{bFGF}$, $1 \% \mathrm{~N} 2,2 \% \mathrm{~B} 27,2 \mathrm{mM}$ glutamine and $1 \%$ penicillin-streptomycin (all from Gibco). Primary stem cell proliferation was detected after 6 days by counting the number of spheres ( $>80 \mu \mathrm{m}$ diameter) of undifferentiated cells. For the neurosphere culture, at least 20 tissue samples for each region were pooled to make each of 3 biological replicates for each. For passaging, dissociated cells from neurospheres were re-seeded in the media with growth factor (P0-P3).

\section{Differentiation protocol}

Glass coverslips (12 mm in diameter; Marienfeld GmbH \& Co. KG, Germany) were placed in 24-well culture plates (SPL, Seoul, Korea) and coated overnight with $15 \mu \mathrm{g} / \mathrm{ml}$ of polyornithine and $5 \mu \mathrm{g} / \mathrm{ml}$ of laminin (Sigma, MO, USA). Seven days after the primary culture, spheres were collected by centrifugation at $200 \mathrm{~g}$, then dissociated with Accutase and mechanically disrupted. The resulting single cells were then washed to remove the enzyme, and seeded onto the coverslips at a density of $5 \mathrm{x}$ $10^{4}$ cells/well. The differentiation assay was done using appropriate differentiation medium for neuron (supplemented $1 \%$ penicillin-streptomycin, B27 supplement, and $2 \mathrm{mM}$ glutamine), astrocyte (supplemented 1\% penicillin-streptomycin, 1\% fetal bovine serum, N2 supplement and $2 \mathrm{mM}$ glutamine) and oligodendrocyte (supplemented $1 \%$ penicillin-streptomycin, B27 supplement, $2 \mathrm{mM}$ glutamine and $30 \mathrm{ng} / \mathrm{ml}$ triiodo-L-thyronine) until day 14. The cultures were allowed to differentiate for 2 - 3 weeks with medium change every 3 days in vitro, after which the differentiation into neurons, astrocytes, and oligodendrocytes was confirmed by immunocytochemistry.

\section{Immunostaining}

Neurospheres were seeded on poly-L-lysine-coated coverslips, incubated for $24 \mathrm{~h}$, and then fixated with $4 \%$ paraformaldehyde (in PBS, $\mathrm{pH}$ 7.2) for 30 minutes. The spheres were washed three times in PBS (10 min 
each) and blocked in $10 \%$ bovine serum albumin (BSA, Gibco) in $0.1 \%$ Triton X-100/PBS at room temperature for $1 \mathrm{~h}$. Primary antibodies (rabbit anti-SOX2 (1:500; Millipore, MO, USA), rabbit anti-nestin (1:500; ProSci, CA, USA), mouse anti-tubulin $\beta 3$ (1:1,000; Abcam, Cambridge, England), rat anti-myelin basic protein (MBP) (1:400; Millipore), and mouse anti-GFAP (1:500; Millipore)) were diluted in PBS/10\% BSA/0.1\% Triton $\mathrm{X}-100$ and incubated overnight at $4{ }^{\circ} \mathrm{C}$. The spheres were then incubated in appropriate secondary antibodies (1:100; Life Technologies, OR, USA) for 30 min at $37^{\circ} \mathrm{C}$. DAPI was used for nuclear counterstain. Fluorescence was detected and photographed using a Zeiss photomicroscope (Carl Zeiss, Jena, Germany).

\section{Statistical analysis}

Statistical analyses were performed using Mann-Whitney $U$ test with Sigma Plot 12 software system. Results were expressed as the mean \pm standard error of the mean (SEM) of triplicate samples and reproducibility was confirmed in at least three independent experiments. A significant difference was defined as $p<0.05$.

\section{Acknowledgements}

This research was supported by Basic Science Research Program through the National Research Foundation of Korea (NRF) funded by the Ministry of Science, ICT \& Future Planning (2015R1A2A1A15055781).

\section{References}

CHRENEK, R., MAGNOTTI, L.M., HERRERA, G.R., JHA, R.M. and CARDOZO, D.L. (2017). Characterization of the filum terminale as a neural progenitor cell niche in both rats and humans. J Comp Neurol 525: 661-675.

COPP, A.J., STANIER, P. and GREENE, N.D. (2013). Neural tube defects: recent advances, unsolved questions, and controversies. Lancet Neurol 12: 799-810.

DIEZ DEL CORRAL, R., BREITKREUZ, D.N. and STOREY, K.G. (2002). Onset of neuronal differentiation is regulated by paraxial mesoderm and requires attenuation of FGF signalling. Development 129: 1681-1691.

FU, S.L., MA, Z.W., YIN, L., IANNOTTI, C., LU, P.H. and XU, X.M. (2005). Regionspecific growth properties and trophic requirements of brain- and spinal cord-derived rat embryonic neural precursor cells. Neuroscience 135: 851-862.

HAMBURGER, V. and HAMILTON, H.L. (1992). A series of normal stages in the development of the chick embryo. 1951. Dev Dyn 195: 231-272.

HENRIQUE, D., ABRANCHES, E., VERRIER, L. and STOREY, K.G. (2015). Neuromesodermal progenitors and the making of the spinal cord. Development 142 : 2864-2875.

JENSEN, J.B. and PARMAR, M. (2006). Strengths and limitations of the neurosphere culture system. Mol Neurobiol 34: 153-161.

KALYANI, A., HOBSON, K. and RAO, M.S. (1997). Neuroepithelial stem cells from the embryonic spinal cord: isolation, characterization, and clonal analysis. Dev
Biol 186: 202-223.

KELLY, T.K., KARSTEN, S.L., GESCHWIND, D.H. and KORNBLUM, H.I. (2009) Cell lineage and regional identity of cultured spinal cord neural stem cells and comparison to brain-derived neural stem cells. PLoS One 4: e4213.

KRENN, V., OSTERMAYER, H. and WACHTLER, F. (1990). On the histogenetic potency of the tailbud mesoderm. Anat Embryol (Berl) 181: 595-601.

LE DOUARIN, N.M. (2001). Early neurogenesis in amniote vertebrates. Int J Dev Biol 45: 373-378.

MULLER, F. and O'RAHILLY, R. (1987). The development of the human brain, the closure of the caudal neuropore, and the beginning of secondary neurulation at stage 12. Anat Embryol (Berl) 176: 413-430.

PASTRANA, E., SILVA-VARGAS, V. and DOETSCH, F. (2011). Eyes wide open: a critical review of sphere-formation as an assay for stem cells. Cell Stem Cell 8: 486-498.

REYNOLDS, B.A. and WEISS, S. (1992). Generation of neurons and astrocytes from isolated cells of the adult mammalian central nervous system. Science 255: $1707-1710$

SCHOENWOLF, G.C. (1979). Histological and ultrastructural observations of tail bud formation in the chick embryo. Anat Rec 193: 131-147.

SCHOENWOLF, G.C. and DELONGO, J. (1980). Ultrastructure of secondary neurulation in the chick embryo. Am J Anat 158: 43-63.

SCHOENWOLF, G.C. and POWERS, M.L. (1987). Shaping of the chick neuroepithelium during primary and secondary neurulation: role of cell elongation. Anat Rec 218: 182-195.

SCOTT, C.E., WYNN, S.L., SESAY, A., CRUZ, C., CHEUNG, M., GOMEZ GAVIRO, M.V., BOOTH, S., GAO, B., CHEAH, K.S., LOVELL-BADGE, R. et al., (2010) SOX9 induces and maintains neural stem cells. Nat Neurosci 13: 1181-1189.

SHAKER, M.R., KIM, J.Y., KIM, H. and SUN, W. (2015). Identification and characterization of secondary neural tube-derived embryonic neural stem cells in vitro. Stem Cells Dev 24: 1171-1181.

SHEDDEN, P.M. and WILEY, M.J. (1987). Early stages of development in the caudal neural tube of the golden Syrian hamster (Mesocricetus auratus). Anat Rec 219: $180-185$

TAVAZOIE, M., VAN DER VEKEN, L., SILVA-VARGAS, V., LOUISSAINT, M., COLONNA, L., ZAIDI, B., GARCIA-VERDUGO, J.M. and DOETSCH, F. (2008). A specialized vascular niche for adult neural stem cells. Cell Stem Cell 3: 279-288.

TEMPLE, S. (2001). The development of neural stem cells. Nature 414: 112-117.

WEISS, S., DUNNE, C., HEWSON, J., WOHL, C., WHEATLEY, M., PETERSON, A.C. and REYNOLDS, B.A. (1996). Multipotent CNS stem cells are present in the adult mammalian spinal cord and ventricular neuroaxis. J Neurosci 16: 7599-7609.

YANG, H.J., LEE, D.H., LEE, Y.J., CHI, J.G., LEE, J.Y., PHI, J.H., KIM, S.K., CHO, B.K. and WANG, K.C. (2014). Secondary neurulation of human embryos: morphological changes and the expression of neuronal antigens. Childs Nerv Syst 30: 73-82.

YANG, H.J., WANG, K.C., CHI, J.G., LEE, M.S., LEE, Y.J., KIM, S.K. and CHO, B.K. (2003). Neural differentiation of caudal cell mass (secondary neurulation) in chick embryos: Hamburger and Hamilton Stages 16-45. Brain Res Dev Brain Res 142: 31-36. 


\section{Further Related Reading, published previously in the Int. J. Dev. Biol.}

Neural crest ontogeny during secondary neurulation: a gene expression pattern study in the chick embryo Liliana Osório, Marie-Aimée Teillet, Isabel Palmeirim and Martin Catala Int. J. Dev. Biol. (2009) 53: 641-648

https://doi.org/10.1387/ijdb.072517lo

Early stages of neural crest ontogeny: formation and regulation of cell delamination Chaya Kalcheim and Tal Burstyn-Cohen

Int. J. Dev. Biol. (2005) 49: 105-116

https://doi.org/10.1387/ijdb.041949ck

Distinct neural precursors in the developing human spinal cord

Sally Walder and Patrizia Ferretti

Int. J. Dev. Biol. (2004) 48: 671-674

https://doi.org/10.1387/ijdb.041853sw

Neurulation in amniote vertebrates: a novel view deduced from the use of quail-chick chimeras

N M Le Douarin, M A Teillet and M Catala

Int. J. Dev. Biol. (1998) 42: 909-916

https://doi.org/10.1387/ijdb.9853821

Morphogenetic features in the tail region of the rat embryo

L Kostovic-Knezevic, S Gajovic and A Svajger

Int. J. Dev. Biol. (1991) 35: 191-195

https://doi.org/10.1387/ijdb.1814401

5 yr ISI Impact Factor $(2013)=2.879$
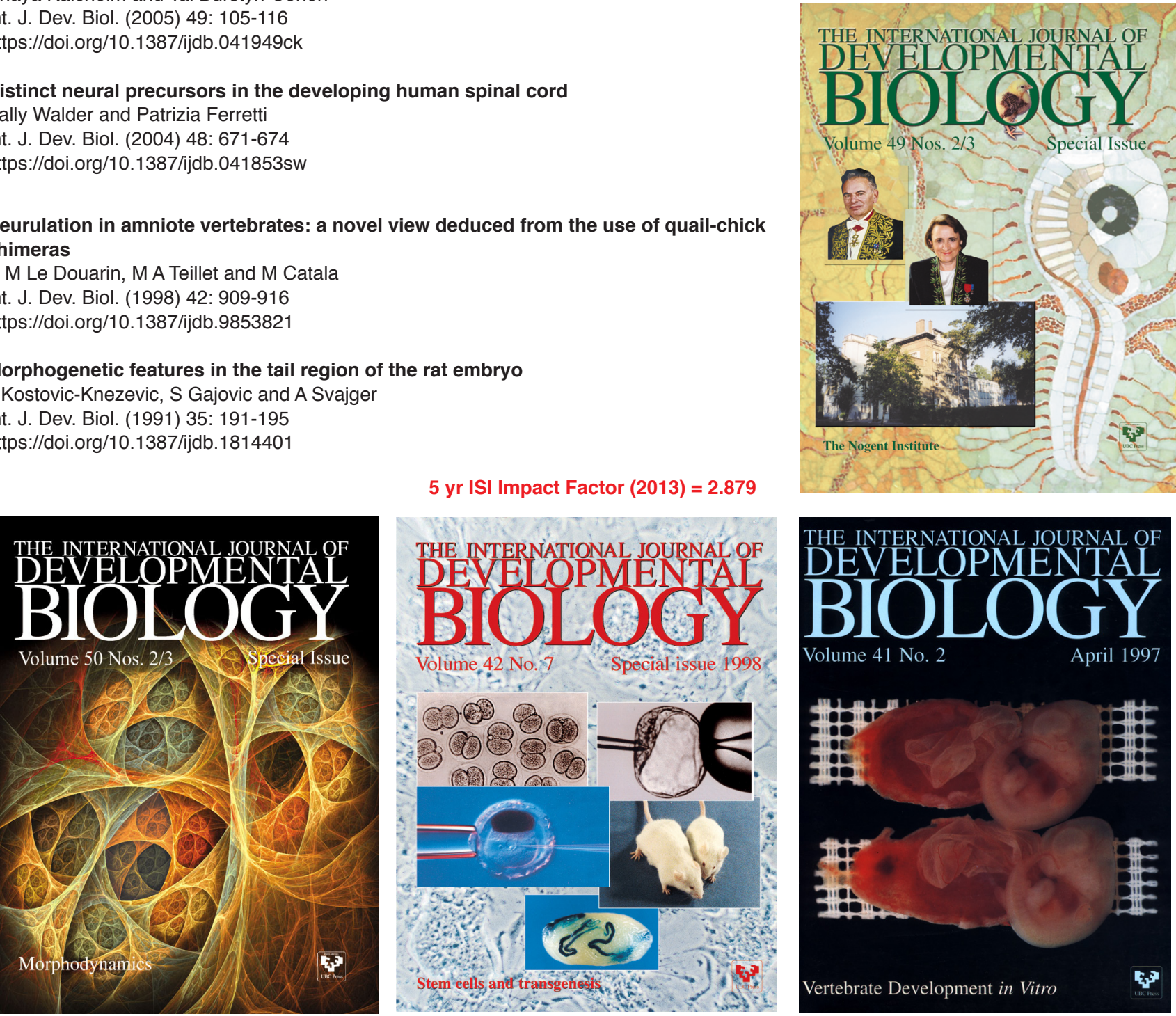

THE INTERNATIONAL JOURNAL OF

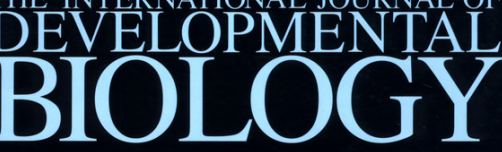

Volume 41 No. 2

April 1997
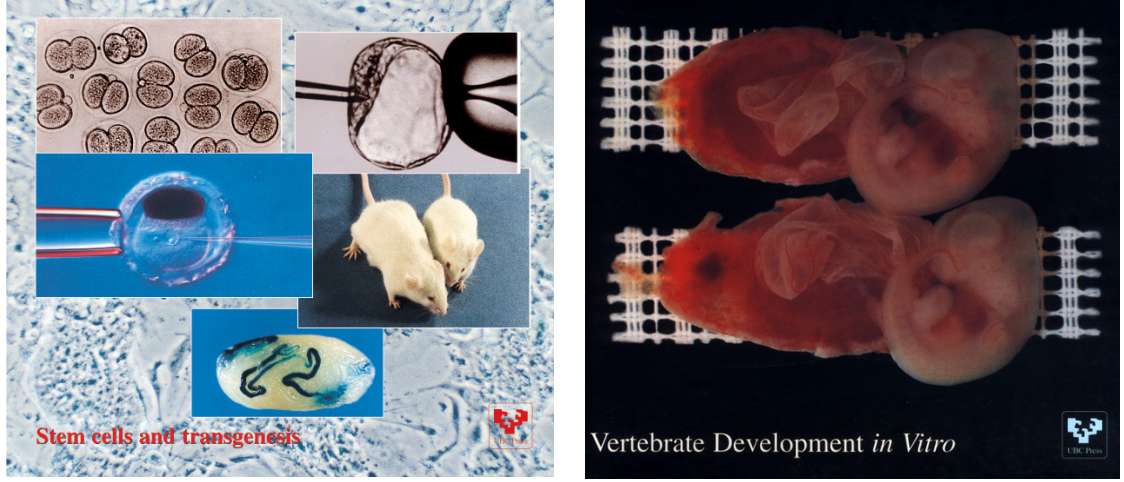